Full length article

\title{
Dual task interference on postural sway, postural transitions and gait in people with Parkinson's disease and freezing of gait
}

\author{
Ana Claudia de Souza Fortaleza ${ }^{\mathrm{a}}$, Martina Mancini ${ }^{\mathrm{b}, *}$, Patty Carlson-Kuhta ${ }^{\mathrm{b}}$, Laurie A. King ${ }^{\mathrm{b}}$, \\ John G. Nutt ${ }^{\mathrm{b}}$, Eliane Ferrari Chagas ${ }^{\mathrm{d}}$, Ismael Forte Freitas Junior ${ }^{\mathrm{a}, \mathrm{e}}$, Fay B. Horak ${ }^{\mathrm{b}, \mathrm{c}}$ \\ a Bioscience Institute, São Paulo State University (UNESP), Rio Claro, SP,13506-900, Brazil \\ b Department of Neurology, School of Medicine, Oregon Health \& Science University,3181 Sam Jackson Park Road, Portland, OR 97239-3098, USA \\ c Department of Research, Portland VA Medical Center, 3710 SW US Veterans Hospital Rd, Portland, OR 97239-9264, USA \\ d Department of Physiotherapy, São Paulo State University (UNESP), Presidente Prudente, SP, 19060-900, Brazil \\ e Department of Physical Education, São Paulo State University (UNESP), Presidente Prudente, SP, 19060-900, Brazil
}

\section{A R T I C L E I N F O}

\section{Keywords:}

Parkinson's disease

Freezing of gait

Dual task

Anticipatory postural adjustments

Gait

\begin{abstract}
A B S T R A C T
Freezing of gait (FoG) is associated with less automatic gait and more impaired cognition, balance and postural transitions compared to people with PD who do not have FoG. However, it is unknown whether dual-task cost during postural sway, postural transitions (such as gait initiation and turning), and gait are more in subjects with Parkinson's disease (PD) who have freezing of gait (FoG +) compared to those who do not have FoG (FoG-). Here, we hypothesized that the effects of a cognitive dual task on postural sway, postural transitions and gait would be larger in FoG + than FoG - . Thirty FoG - and 24 FoG + performed an Instrumented Stand and Walk test in OFF medication state, with and without a secondary cognitive task (serial subtraction by 3s). Measures of postural sway, gait initiation, turning, and walking were extracted using body-worn inertial sensors. FoG + showed significantly larger dual task cost than FoG - for several gait metrics, but not during postural sway or postural transitions. During walking, FoG + exhibited a larger dual task cost than FoG - resulting in shorter stride length and slower stride velocity. During standing, FoG + showed a larger postural sway compared to FoG - and during gait initiation, FoG + , but not FoG - , showed a longer first step duration during the dual-task condition compared to single-task condition (interaction effect, $\mathrm{p}=0.04$ ). During turning, both groups showed a slower turn peak speed in the dual-task condition compared to single task condition. These findings partly support our hypothesis that dual task cost on walking is greater in FoG + than FoG - .
\end{abstract}

\section{Introduction}

Freezing of gait (FoG), defined as the "absence or marked reduction of the forward progression of the feet, despite the intention to walk" is a poorly understood phenomenon that eventually affects $80 \%$ of people with Parkinson's disease (PD) [1]. FoG impairs quality of life [2], increases fall risk and results in lack of independence [3]. Freezing is more often triggered by postural transitions, such as step initiation or turning, than straight-ahead gait [4].

Subjects with PD and FoG (FoG +) usually present with more cognitive impairments compared to subjects with PD without FoG (FoG-), including deficits in executive function, attention, working memory and visuospatial domains that can interfere with mobility [5]. Gait and posture control are abilities that once learned should be automatic [1], meaning one's attention does not need to be directed toward the details of the movement [6]. However, FoG + may need cognitive input for control of gait and postural transitions to compensate for their loss of automatic control [7]. When cognitive attention is used to control gait and posture, a decline in ability to perform cognitive and motor tasks simultaneously, called dual-task cost, is larger [8]. Subjects with cognitive impairments may show a decline in dual-task ability, that are important for daily activities (crossing the street while attending to traffic, walking while talking, etc.), and functional independence [9].

It is unclear if postural sway and postural transitions, such as anticipatory postural adjustments (APAs) phase prior to gait initiation or changing direction while walking, are more or less automatic than ongoing gait, and thereby more or less affected by a secondary, dual task. A recent study from Tard et al. [10] showed that an attentional load in the anticipatory phase of gait initiation, represented by an

\footnotetext{
* Corresponding author.

E-mail addresses: anaclaudiafisiouel@yahoo.com.br (A.C. de Souza Fortaleza), mancinim@ohsu.edu (M. Mancini), carlsonp@ohsu.edu (P. Carlson-Kuhta), kingla@ohsu.edu (L.A. King), paivachagas@uol.com.br (E.F. Chagas), ismael@fct.unesp.br (I.F. Freitas), horakf@ohsu.edu (F.B. Horak).
} 
auditory stimulus, caused a more frequent occurrence of inappropriate APAs (APAs not followed by step execution) in FoG + compared to FoG - (ON medication) and older controls. Generally, subjects with PD release prolonged and reduced amplitude APAs due to reduced lateral shift of the body mass over the stance limb, and those with freezing of gait often show large, multiple APAs.

Differences between FoG - and FoG + in gait characteristics during a cognitive dual-task have been previously investigated [13-15]. Results showed that FoG + showed larger dual task costs during walking than FoG -, with greater increase in stride length, increase in number of steps and reduction of gait velocity $[13,14]$. FoG + show worse postural control than FoG - , assessed with the Fullerton Advance Balance scale in the ON medication state [16]. However, there are no studies comparing dual task interference on postural transitions (turning and gait initiation) and postural sway between FoG - and FoG + .

Turning may be a less automatic task than straight ahead walking because it requires complex control of dynamic balance and sequential whole body coordination [17]. However, only one study [14] investigated the influence of a cognitive task while turning 180 and $360^{\circ}$ in FoG + and FoG - . The authors found that only FoG + needed more steps during the cognitive dual task to complete the turn, and took a longer time to complete the 180 degree-turning with dual task. All 3 groups, including elderly control subjects, took a longer time to turn $360^{\circ}$ with a dual task.

The current study compared the effects of a cognitive dual-task between FoG + and FoG - during postural sway in standing, postural transitions, and straight-ahead gait. To our knowledge, this is the first study to compare dual task interference on a variety of motor tasks in the same subject group and the first study to compare dual task interference between FoG + and FoG - in the OFF levodopa state. We hypothesized that dual task cost on postural sway, APAs, initial step characteristics, turning and walking will be larger in FoG + compared to FoG - .

\section{Methods}

\subsection{Subjects}

Fifty-six subjects with PD subjects recruited through the Parkinson's Center of Oregon at Oregon Health \& Science University (OHSU) and VA Portland Health Care System (VAPORHCS). Subjects were excluded if they presented: neurological diseases other than PD, vestibular disorders, musculoskeletal impairments that could affect gait, and inability to stand and walk unassisted. Fifteen healthy elderly adults of similar age were recruited from the community. All participants provided informed consent approved by the OHSU Institutional Review Board.

\subsection{Procedure}

Testing was carried out in the practical OFF levodopa state (after at least $12 \mathrm{~h}$ withdrawal from their antiparkinson medication). Subjects with PD were clinically rated by a trained examiner on the Motor Section (III) of the Unified Parkinson's Disease Rating Scale (MDSUPDRS) prior to the mobility assessment which consists of 23 items related to bradykinesia, rigidity, tremor and posture and gait signs rated on a 4-point scale [19]. The Posture Instability and Gait Disability subscore (PIGD) was also calculated from the MDS-UPDRS Part III [20].Balance function was clinically assessed with the mini-BESTest, a clinical test including 14 items (best score of 28) related to anticipatory and reactive postural control, sensory orientation, and dynamic gait [21]. General cognition was assessed with the Montreal Cognitive Assessment (MoCA).

Subjects with PD were divided into non-freezers (FoG-), $\mathrm{N}=30$, and freezers $(\mathrm{FoG}+), \mathrm{N}=24$ based on their answer to question 1 of the New Freezing of Gait Questionnaire (NFOGQ): "Have you experienced
FoG in the past month?" [18].

\subsection{Mobility assessment}

Eight Opal inertial sensors (APDM, Inc) were worn on: both feet, shanks, wrists, chest, and posterior trunk at the level of L5 with elastic Velcro bands while the subjects performed the Instrumented Stand and Walk test (SAW) [11]. Inertial sensor data was collected and wirelessly streamed to a laptop for automatic generation of gait and balance metrics by Mobility Lab software (APDM, Inc). In the SAW test, subjects are asked to stand quietly for $30 \mathrm{~s}$, instructed when to walk seven meters at their comfortable speed, turn $180^{\circ}$, and walk back. The test was performed first, without a secondary, cognitive task and then with a cognitive task, that consisted of serial subtraction by $3 \mathrm{~s}$ from either 223 (baseline, while they were seated) or 206 (during the cognitive task). In the dual task condition, no instructions were given on which task to prioritize. The tests were conducted by trained research assistants who walked behind and close to participants for safety.

To assess the cognitive task performance in the baseline condition, we recorded correct and incorrect responses that were generated in $60 \mathrm{~s}$ with a portable microphone on the subjects' shirt. The same responses were recorded in the dual-task condition.

Based on good-to-excellent reliability [22,23], the following measures were used to assess postural sway, postural transitions and gait: 1) Postural sway: root mean square (RMS) and sway jerkiness (JERK) both in antero-posterior (AP) and medio-lateral (ML) directions 2) Step Initiation: APA peak amplitude in the AP and ML directions, APA duration, first step Range of Motion (ROM), and first step duration; 3) Turning: turning peak velocity and turning duration; 4) Walking: stride length and stride velocity. The first step at gait initiation and steps during turn were automatically excluded by the gait algorithm for the stride length and stride velocity measures.

To quantify subjects' ability to execute two tasks concurrently, we calculated the dual task costs (DTC), for both motor and cognitive tasks. Dual-task cost in motor performance was calculated as DTC [\%] $=100$ * (dual-task motor measure - single-task motor measure)/single-task motor measure. Dual-task cost in cognitive performance was calculated using the same equation considering the percentage of correct answers in serial subtraction while the subjects were seated (as a single-task cognitive measure) and the percentage of correct answers while performing the SAW with dual-task.

\subsection{Statistical analysis}

Data from the 15 control subjects were used as reference and not statistically compared with the 2 PD groups. Homogeneity of variance between the FoG + and FoG - groups was verified using Levene's test. To investigate the dual-task effects in postural sway, gait initiation, turning and walking we used a two-way ( 2 groups $\times 2$ conditions) repeated measures analysis of variance (ANOVA) between groups $(\mathrm{FoG}+/ \mathrm{FoG}-)$ and within conditions (single task/dual task). To confirm the dual task effect, we performed a Student's $t$-test $(\mathrm{p}<0.05)$ in dual task cost motor measures. In addition, a Student's $t$-test was also used to investigate differences in: age, MDS-UPDRS III, PIGD, mini-BESTest, MoCA, and dual-task cost in cognitive performance among FoG + and FoG - . Statistical analyses were performed using SPSS (IBM V.22).

\section{Results}

\subsection{Subject characteristics}

No differences were observed between FoG - and FoG + groups in age, severity of disease (assessed by MDS-UPDRS III), or general cognitive function (MoCA). Balance (mini-BESTest) and the PIGD subscore were significantly worse in FoG + compared to FoG-. 
Table 1

Subjects demographics and clinical measures.

\begin{tabular}{|c|c|c|c|c|}
\hline Measure & Group & Mean & STD & p-value \\
\hline \multirow[t]{2}{*}{ Age (years) } & FoG - & 68.6 & 8.4 & 0.77 \\
\hline & FoG + & 69.2 & 7.9 & \\
\hline \multirow[t]{2}{*}{ Gender } & FoG - & $21 \mathrm{M}-9 \mathrm{~F}$ & - & \\
\hline & FoG + & $21 \mathrm{M}-5 \mathrm{~F}$ & - & \\
\hline \multirow{2}{*}{ NFoG - Q (score) } & FoG - & - & - & \\
\hline & FoG + & 14.3 & 6.4 & \\
\hline \multirow[t]{2}{*}{ Disease Severity (years) } & FoG - & 6.3 & 4.1 & 0.52 \\
\hline & FoG + & 8.3 & 5.3 & \\
\hline \multirow[t]{2}{*}{ Levodopa Equivalent Dose (mg/day) } & FoG - & 711.1 & 360.8 & 0.10 \\
\hline & FoG + & 875.5 & 1320.6 & \\
\hline \multirow[t]{2}{*}{ MDS-UPDRS III } & FoG - & 38.7 & 9.0 & 0.09 \\
\hline & FoG + & 43.1 & 10.0 & \\
\hline \multirow[t]{2}{*}{ PIGD subscore } & FoG - & 4.5 & 2.8 & 0.01 \\
\hline & FoG + & 6.8 & 3.8 & \\
\hline \multirow[t]{2}{*}{ mini-BEST } & FoG - & 19.6 & 4.3 & 0.008 \\
\hline & FoG + & 15.8 & 5.6 & \\
\hline \multirow[t]{2}{*}{ MoCA } & FoG - & 25.0 & 3.2 & 0.75 \\
\hline & FoG + & 24.9 & 4.2 & \\
\hline \multirow[t]{2}{*}{ Correct answers seated (\%) } & FoG - & 94.7 & 4.4 & 0.06 \\
\hline & FoG + & 87.6 & 15.9 & \\
\hline
\end{tabular}

FoG-group $(\mathrm{n}=30)$; FoG + group $(\mathrm{n}=26)$ Statistically significant differences are bolded.

Table 1 summarizes the subjects' characteristics.

\subsection{Postural sway}

FoG + did not show larger dual task cost than FoG- during standing. A significant group effect was found for RMS AP ( $F=4.69$; $\mathrm{p}=0.03$ ), with larger sway dispersion in FoG + compared to FoG - , but with no significant condition or interaction effect (See Table 2 and Fig. 1). No significant differences between groups or conditions were present for RMS ML, JERK-AP or JERK-ML.

\subsection{Postural transitions}

\subsubsection{Gait initiation}

The execution phase (first step characteristics), but not the anticipatory phase, of gait initiation showed larger dual task cost in FoG + compared to FoG - . A significant group $\mathrm{x}$ dual task condition interaction effect was observed for the first step duration $(F=5.26 ; p=0.02$ ) (Table 2 and Fig. 1), with a longer first step duration during the dualtask compared to single-task in FoG +, and an opposite trend in FoG - . However, no significant group ( $\mathrm{F}=0.02 ; \mathrm{p}=0.87$ ) or condition effects $(\mathrm{F}=1.39 ; \mathrm{p}=0.24)$ were observed. None of the other gait initiation measures (APA characteristics or First Step Length) showed a significant group, condition or interaction effect.

\subsubsection{Turning}

FoG + did not show larger dual task cost than FoG - during turning. Significant group $(\mathrm{F}=6.70 ; \mathrm{p}=0.012)$ and condition $(\mathrm{F}=12.56$; $\mathrm{p}=0.001$ ) effects were observed for turning peak speed, with slower turn speed in FoG + compared to FoG -, and slower turn speed in the dual task condition compared to the single task condition (Table 2 and Fig. 1). However, no significant interaction between group and dual task condition was found.

\subsection{Gait}

FoG + showed larger dual task cost on walking than FoG-. Significant group, condition, and interaction effects were observed for
Stride Length and Stride Velocity during straight-ahead gait (Table 2 and Fig. 1). Both FoG - and FoG + showed significantly shorter step length and slower stride velocity during dual task compared to single task. In addition, FoG + exhibited significant shorter stride length and slower stride velocity compared to FoG - both in single, and dual-task conditions.

\subsection{Dual task cost in motor performance}

Consistent with the ANOVA results, when running an independent $t$ test on the dual task cost, we observed that FoG + showed a significantly larger dual-task cost compared to FoG - for: 1) first step duration $(-0.80 \%$ versus $32.1 \%),(\mathrm{p}=0.030)$, 2) stride length $(-8.313 \%$ versus $-20.03 \%)(\mathrm{p}=0.005)$ and 3$)$ stride velocity $(-12.57 \%$ versus $-25.95 \%)(\mathrm{p}=0.006)$. Similar dual-task costs for FoG + and FoG - were observed for all the other metrics.

\subsection{Dual task cost in cognitive performance}

We did not observe differences in dual task-cost during cognitive performance between groups $(-2.2 \%$ versus $0.10 \%)$, $(\mathrm{p}=0.7)$.

\section{Discussion}

This is the first study comparing the effects of a dual task on postural sway, postural transitions and walking in the same subjects. FoG + showed a larger dual task costs than FoG - while walking, but not during postural sway. The tests were performed in OFF state of levodopa since previous study of these laboratory [11] showed that dopamine replacement medication improves some gait and postural transition characteristics like stride length, stride duration, and APA size, while it worsens other measures such as postural sway, turning duration.

FoG + showed larger dual task costs compared to FoG - on stride length $(-20.68 \%$ versus $-8.32 \%)$ and velocity $(-27.24 \%$ and $-12.57 \%$ ) during walking. These interaction effects suggest that FoG + require more attention than FoG - to generate large and fast steps, whether the first or ongoing steps, partly consistent with our hypothesis. However, the results did not support our hypothesis that dual task costs on postural sway and postural transitions (initiation and turning) would also be larger in FoG + than FoG - .

\subsection{Dual task cost on postural sway}

Sway dispersion was not affected by the dual task in either FoG + or FoG-, although the AP sway dispersion was larger in the FoG + compared to FoG - . This is in keeping with recent findings showing impaired postural control in FoG + compared to FoG - [16]. We hypothesized that sway dispersion or smoothness would be affected by dual task since executive and memory functions have been found to be related to postural instability assessed by the PIGD subscore [24]. However, although we found differences between groups in PIGD and in the MiniBESTest, we did not see a dual-task interference during postural sway in FoG + compared to FoG -, which may be explained by the fact that both groups were cognitively intact, as the MoCA scores were similar.

\subsection{Dual task cost on step initiation}

FoG + showed a larger dual task cost on first step duration compared to FoG -, with only FoG + increasing the duration of their first step in the postural transition phase. The slowing of the first step in the FoG + group with a dual task may represent start hesitation but no clinically apparent freezing. We did not find any difference in dual task cost on APA measures between groups and the other APA measures were similar in FoG + and FoG -. 
Table 2

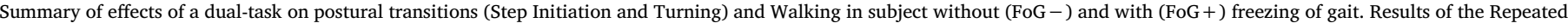
Measure ANOVA are reported on the right. Statistically significant differences are bolded.

\begin{tabular}{|c|c|c|c|c|c|c|c|}
\hline $\begin{array}{l}\text { Postural Sway } \\
\text { Measure }\end{array}$ & Group & $\begin{array}{l}\text { Single Task } \\
\text { Mean } \pm \text { STD }\end{array}$ & $\begin{array}{l}\text { Dual-task } \\
\text { Mean } \pm \text { STD }\end{array}$ & & Group & Condition & Interaction \\
\hline RMS ML (m/s $\left.{ }^{2}\right)$ & $\begin{array}{l}\text { FoG - } \\
\text { FoG }+\end{array}$ & $\begin{array}{l}0.070 \pm 0.030 \\
0.063 \pm 0.049\end{array}$ & $\begin{array}{l}0.079 \pm 0.034 \\
0.068 \pm 0.064\end{array}$ & $\begin{array}{l}\text { F-value } \\
\text { p-value }\end{array}$ & $\begin{array}{l}0.60 \\
0.44\end{array}$ & $\begin{array}{l}0.96 \\
0.33\end{array}$ & $\begin{array}{l}0.14 \\
0.71\end{array}$ \\
\hline RMS AP $\left(\mathrm{m} / \mathrm{s}^{2}\right)$ & $\begin{array}{l}\text { FoG - } \\
\text { FoG + }\end{array}$ & $\begin{array}{l}0.029 \pm 0.022 \\
0.062 \pm 0.073\end{array}$ & $\begin{array}{l}0.034 \pm 0.024 \\
0.047 \pm 0.046\end{array}$ & $\begin{array}{l}\text { F-value } \\
\text { p-value }\end{array}$ & $\begin{array}{l}4.69 \\
0.03\end{array}$ & $\begin{array}{l}0.61 \\
0.44\end{array}$ & $\begin{array}{l}3.16 \\
0.08\end{array}$ \\
\hline JERK ML $\left(\mathrm{m}^{2} / \mathrm{s}^{5}\right)$ & $\begin{array}{l}\text { FoG - } \\
\text { FoG }+\end{array}$ & $\begin{array}{l}1.32 \pm 2.12 \\
2.53 \pm 7.69\end{array}$ & $\begin{array}{l}2.89 \pm 7.76 \\
1.64 \pm 1.85\end{array}$ & $\begin{array}{l}\text { F-value } \\
\text { p-value }\end{array}$ & $\begin{array}{l}0.00 \\
0.99\end{array}$ & $\begin{array}{l}0.14 \\
0.71\end{array}$ & $\begin{array}{l}1.79 \\
0.18\end{array}$ \\
\hline JERK AP $\left(\mathrm{m}^{2} / \mathrm{s}^{5}\right)$ & $\begin{array}{l}\text { FoG - } \\
\text { FoG }+\end{array}$ & $\begin{array}{l}1.02 \pm 0.65 \\
2.83 \pm 3.91\end{array}$ & $\begin{array}{l}1.86 \pm 1.45 \\
2.90 \pm 4.19\end{array}$ & $\begin{array}{l}\text { F-value } \\
\text { p-value }\end{array}$ & $\begin{array}{l}3.71 \\
0.05\end{array}$ & $\begin{array}{l}2.67 \\
0.10\end{array}$ & $\begin{array}{l}3.78 \\
0.05\end{array}$ \\
\hline Step Initiation & & Single Task & Dual-task & Statistics & & & \\
\hline Measure & & Mean \pm STD & Mean \pm STD & & Group & Condition & Interaction \\
\hline APA-Peak ML (g) & $\begin{array}{l}\text { FoG - } \\
\text { FoG }+\end{array}$ & $\begin{array}{l}0.033 \pm 0.017 \\
0.029 \pm 0.016\end{array}$ & $\begin{array}{l}0.033 \pm 0.023 \\
0.031 \pm 0.021\end{array}$ & $\begin{array}{l}\text { F-value } \\
\text { p-value }\end{array}$ & $\begin{array}{l}0.73 \\
0.40\end{array}$ & $\begin{array}{l}0.11 \\
0.74\end{array}$ & $\begin{array}{l}0.16 \\
0.69\end{array}$ \\
\hline APA-Peak AP (g) & $\begin{array}{l}\text { FoG - } \\
\text { FoG }+\end{array}$ & $\begin{array}{l}0.039 \pm 0.017 \\
0.032 \pm 0.022\end{array}$ & $\begin{array}{l}0.045 \pm 0.031 \\
0.033 \pm 0.023\end{array}$ & $\begin{array}{l}\text { F-value } \\
\text { p-value }\end{array}$ & $\begin{array}{l}3.37 \\
0.07\end{array}$ & $\begin{array}{l}0.72 \\
0.40\end{array}$ & $\begin{array}{l}0.28 \\
0.59\end{array}$ \\
\hline APA duration(s) & $\begin{array}{l}\text { FoG - } \\
\text { FoG }+\end{array}$ & $\begin{array}{l}1.03 \pm 1.45 \\
0.72 \pm 0.76\end{array}$ & $\begin{array}{l}0.57 \pm 0.17 \\
0.64 \pm 0.33\end{array}$ & $\begin{array}{l}\text { F-value } \\
\text { p-value }\end{array}$ & $\begin{array}{l}0.46 \\
0.50\end{array}$ & $\begin{array}{l}2.70 \\
0.11\end{array}$ & $\begin{array}{l}1.39 \\
0.24\end{array}$ \\
\hline $1^{\text {st }}$ Step ROM $\left(^{\circ}\right)$ & $\begin{array}{l}\text { FoG - } \\
\text { FoG }+\end{array}$ & $\begin{array}{l}35.52 \pm 4.87 \\
29.54 \pm 8.30\end{array}$ & $\begin{array}{l}33.39 \pm 7.31 \\
31.06 \pm 10.64\end{array}$ & $\begin{array}{l}\text { F-value } \\
\text { p-value }\end{array}$ & $\begin{array}{l}1.79 \\
0.19\end{array}$ & $\begin{array}{l}1.00 \\
0.33\end{array}$ & $\begin{array}{l}0.14 \\
0.71\end{array}$ \\
\hline $1^{\text {st }}$ Step Duration(s) & $\begin{array}{l}\text { FoG - } \\
\text { FoG }+\end{array}$ & $\begin{array}{l}0.43 \pm 0.12 \\
0.38 \pm 0.09\end{array}$ & $\begin{array}{l}0.40 \pm 0.15 \\
0.45 \pm 0.17\end{array}$ & $\begin{array}{l}\text { F-value } \\
\text { p-value }\end{array}$ & $\begin{array}{l}0.01 \\
0.91\end{array}$ & $\begin{array}{l}1.04 \\
0.31\end{array}$ & $\begin{array}{l}4.40 \\
0.04\end{array}$ \\
\hline $\begin{array}{l}\text { Turning } \\
\text { Measure }\end{array}$ & & $\begin{array}{l}\text { Single Task } \\
\text { Mean } \pm \text { STD }\end{array}$ & $\begin{array}{l}\text { Dual-task } \\
\text { Mean } \pm \text { STD }\end{array}$ & & Group & Condition & Interaction \\
\hline Turning Peak Speed & $\begin{array}{l}\text { FoG - } \\
\text { FoG }+\end{array}$ & $\begin{array}{l}140.8 \pm 48.5 \\
117.6 \pm 26.6\end{array}$ & $\begin{array}{l}130.6 \pm 37.7 \\
105.5 \pm 25.3\end{array}$ & $\begin{array}{l}\text { F-value } \\
\text { p-value }\end{array}$ & $\begin{array}{l}6.70 \\
\mathbf{0 . 0 1 2}\end{array}$ & $\begin{array}{l}12.56 \\
0.001\end{array}$ & $\begin{array}{l}0.21 \\
0.65\end{array}$ \\
\hline Turning Duration & $\begin{array}{l}\text { FoG - } \\
\text { FoG }+\end{array}$ & $\begin{array}{l}2.53 \pm 0.51 \\
3.03 \pm 1.05\end{array}$ & $\begin{array}{l}2.74 \pm 0.57 \\
2.89 \pm 0.50\end{array}$ & $\begin{array}{l}\text { F-value } \\
\text { p-value }\end{array}$ & $\begin{array}{l}3.62 \\
0.06\end{array}$ & $\begin{array}{l}0.03 \\
0.85\end{array}$ & $\begin{array}{l}2.77 \\
0.10\end{array}$ \\
\hline $\begin{array}{l}\text { Walking } \\
\text { Measure }\end{array}$ & & $\begin{array}{l}\text { Single Task } \\
\text { Mean } \pm \text { STD }\end{array}$ & $\begin{array}{l}\text { Dual-task } \\
\text { Mean } \pm \text { STD }\end{array}$ & & Group & Condition & Interaction \\
\hline Stride Length (m) & $\begin{array}{l}\text { FoG - } \\
\text { FoG }+\end{array}$ & $\begin{array}{l}1.06 \pm 0.15 \\
0.92 \pm 0.22\end{array}$ & $\begin{array}{l}0.97 \pm 0.14 \\
0.76 \pm 0.28\end{array}$ & $\begin{array}{l}\text { F-value } \\
\text { p-value }\end{array}$ & $\begin{array}{l}10.33 \\
0.002\end{array}$ & $\begin{array}{l}112.88 \\
<0.001\end{array}$ & $\begin{array}{l}8.32 \\
0.006\end{array}$ \\
\hline Stride Velocity $(\mathrm{m} / \mathrm{s})$ & $\begin{array}{l}\text { FoG - } \\
\text { FoG }+\end{array}$ & $\begin{array}{l}0.99 \pm 0.18 \\
0.86 \pm 0.21\end{array}$ & $\begin{array}{l}0.86 \pm 0.16 \\
0.66 \pm 0.27\end{array}$ & $\begin{array}{l}\text { F-value } \\
\text { p-value }\end{array}$ & $\begin{array}{l}9.02 \\
0.004\end{array}$ & $\begin{array}{l}122.33 \\
<0.001\end{array}$ & $\begin{array}{l}5.97 \\
0.018\end{array}$ \\
\hline
\end{tabular}

In agreement with our study, Roemmich et al. [25] did not find dual task interference in APAs in subjects with PD in the ON state, showing a possible posture over cognitive prioritization in PD compared to agematched and younger adult control subjects, since subjects with PD gave less correct answers in cognitive task than young and older control subjects. We found no differences in APA magnitude and duration between FoG + and FoG -, like a previous study [26]. However, other studies have described multiple APAs [27] and APAs released at an inappropriate time on FoG + [10]. Future studies should consider comparing multiple APAs and timing of APAs with a dual task in FoG + compared to FoG - .

A potential confounder of our results on APAs is represented by the instructions we gave the subjects. For example, the examiner said the word 'Walk' to cue the subjects to start walking. This external command could have triggered a faster and more efficient preparation of the first step [26]. Also, the fact that the subjects were probably not actively subtracting while initiating a step or turning, because of the very short duration of these postural transitions, may have resulted in the similar APA observed in single and dual task conditions. We can consider these as two limitations of our study.

Although we didn't find differences in APAs between FoG + and
FoG - , we found that only FoG + increased the first step duration with a dual task. Locomotor network alterations associated in people with FoG + may explain differences between groups. Compared to FoG -, PD FoG + have less white matter connections from the pedunculopontine nucleus to the cerebellar locomotor regions, thalamus, the supplementary motor area (SMA) and prefrontal cortex in the right hemisphere [7]. These pathways are thought to be responsible for response inhibition and gait initiation [7]. Moreover, left hemisphere-lateralized pedunculopontine nucleus tract volume in FoG + is related to poorer performance in speed on tasks requiring the initiation of appropriate actions [28]. The SMA receives internal cues from the basal ganglia to coordinate anticipatory postural adjustments with step initiation. As PD progresses, SMA deteriorates and may lose its ability to sequence postural adjustments and stepping. Subjects in the early stage of PD compensate for basal ganglia dysfunction with greater functional connectivity between the subthalamic nucleus and SMA loop, which is not seen in individuals with FoG + [7].

\subsection{Dual task cost on turning}

Individuals with FoG + showed slower turning peak speed thant 
Gait, Stride Length

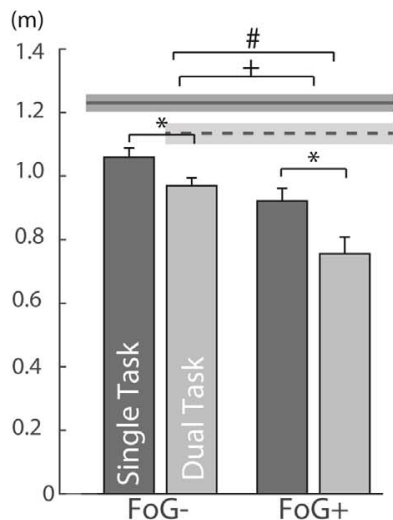

(s) Turn, Turning Peak Velocity

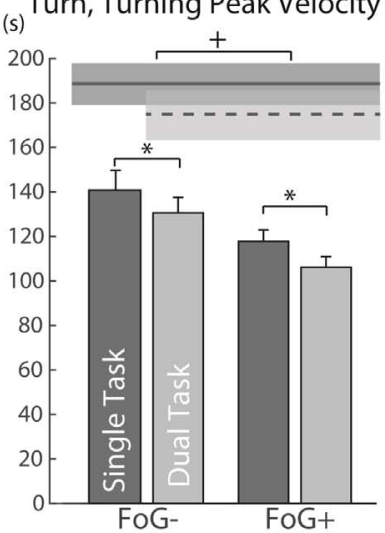

APA, First Step Duration

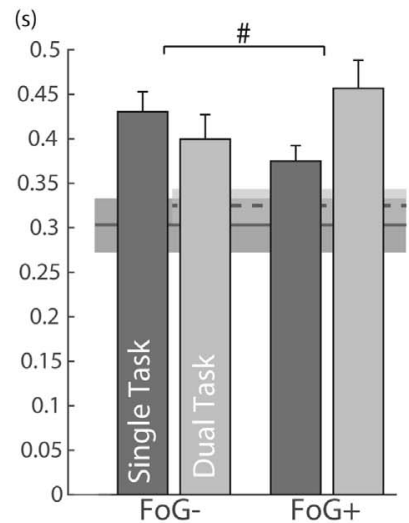

$\left(\mathrm{m}^{2} / \mathrm{s}^{5}\right)$

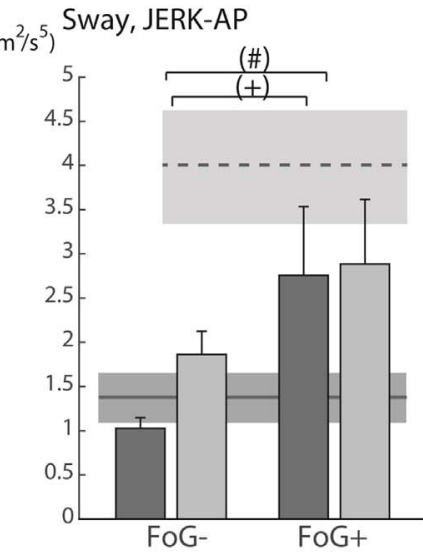

Fig. 1. Main significant differences found in postural transitions and walking in subjects with PD without (FoG-) and with (FOG +) freezing of gait while performing the single task (dark bars) and dual task (lighter bars) Stand and Walk Test (SAW). Mean and SEM of healthy controls (dark grey shaded area for single task and light grey shaded area for dual task) are also reported for comparison, but not used for statistical analysis. + indicates a significant group effect ( $\mathrm{p}<0.05$ ); * indicates a significant condition effect $(\mathrm{p}<0.05)$; and \# indicates a significant interaction effect $(\mathrm{p}<0.05)$. Sway Jerk shows close to significance grop and interaction effects at $\mathrm{p}=0.05(+)$ and (\#)

FoG - . Both FoG + and FoG - reduced peak turning speed in the dual task conditions, compared to the single taskand turned similarly while turning and dual tasking. Contrary to our results, Spildoren et al. [14] found a significant dual-task cost in turning only in FoG + . Several differences between studies could explain this discrepancy: first, the FoG + has worse cognitive function than the FoG - in the study by Spildoren et al., while in our study the MoCA score was similar between groups. Second, Spildoren et al. found the largest difference among FoG + and FoG - during a $360^{\circ}$ turn, while here we are exclusively look at $180^{\circ}$ turn preceded and followed by walking. Third, and this represent also a limitation of the current study, we did not provide specific instructions on prioritization for the dual task and subjects may have not been actively dual tasking for the short duration of the turn.

\subsection{Dual-task cost on gait}

FoG + showed larger dual task costs than FoG - on stride length and stride velocity during walking. These interaction effects suggest that FoG + require more attention than FoG - to generate large and fast steps, whether the first, or ongoing, steps. Other studies reported similar findings [13-15,29] and the majority of them attributed the worse gait performance under dual task to the so-called "posturesecond" strategy [30]. Consistent with a "posture-second" strategy cognitive task errors in our study were the same when sitting and during the Stand and Walk test, suggesting that the cognitive task was prioritized over the posture task in FoG + . Similar to our results, a previous study showed that FoG + exhibited a larger reduction in stride length than FoG - during a dual-task with similar number of errors in the choice reaction times in both groups [15].

Decreased performance in walking while simultaneously performing another task could indicate inability to quickly switch attention between the cognitive and walking tasks or lack of automaticity of the walking task. Impairments in prefrontal brain circuity in FoG + compared to FoG - could explain differences in dual task cost between these groups. It has been proposed that the greater functional connectivity between the SMA and the MLR in FoG + may be associated with increased cognitive control of gait [7]. Moreover, previous studies from our laboratory showed that dual-task interference (in stride length) was correlated with asymmetry of pedunculopontine nucleus structural connectivity only in FoG + [15].

\subsection{Conclusions}

This was the first study to compare dual task cost across different domains of balance and gait in FoG - and FoG +. FoG + were more affected by the dual task than FoG - on first step duration and ongoing gait. These results emphasize the importance of including a dual-task paradigm in gait rehabilitation programs for PD and to practice gait initiation under dual task conditions in patients who have FoG + .

\section{Conflict of interest}

OHSU and Dr. Horak have a significant financial interest in, and are employees of ADPM, a company that has a commercial interest in the results of this research and technology. This potential institutional and individual conflict has been reviewed and managed by OHSU and the VA Portland Health Care System.

\section{Acknowledgement}

We thank Natassja Pal, Heather Schlueter, Michael Fleming, Graham Harker, and Peter Martin for scheduling and helping with data collection. This publication was made possible with support from NIH2R01 AG006457 (Horak), VA MeritI01 RX001075 (Horak), and NIH Career Development AwardK99 HD078492 01A1 (Mancini).

\section{References}

[1] J.G. Nutt, B.R. Bloem, N. Giladi, M. Hallett, F.B. Horak, A. Nieuwboer, Freezing of gait: moving forward on a mysterious clinical phenomenon, Lancet Neurol. 10 (2011) 734-744.

[2] C.C. Walton, J.M. Shine, J.M. Hall, C. O'Callaghan, L. Mowszowski, M. Gilat, et al., The major impact of freezing of gait on quality of life in Parkinson's disease, J. Neurol. 262 (2015) 108-115.

[3] Y. Okuma, Freezing of gait and falls in Parkinson's disease, J. Parkinson's Dis. 4 (2014) 255-260.

[4] J.V. Jacobs, J.-S. Lou, J.A. Kraakevik, F.B. Horak, The supplementary motor area contributes to the timing of the anticipatory postural adjustment during step initiation in participants with and without Parkinson's disease, Neuroscience 164 (2009) 877-885.

[5] D.S. Peterson, L.A. King, R.G. Cohen, F.B. Horak, Cognitive contributions to freezing of gait in Parkinson disease: implications for physical rehabilitation, Phys. Ther. 96 (2016) 659-670.

[6] T. Wu, M. Hallett, P. Chan, Motor automaticity in Parkinson's disease, Neurobiol. Dis. 82 (2015) 226-234.

[7] B.W. Fling, R.G. Cohen, M. Mancini, S.D. Carpenter, D.A. Fair, J.G. Nutt, et al., Functional reorganization of the locomotor network in Parkinson patients with freezing of gait, PLoS One 9 (2014) e100291.

[8] R. Parihar, J.R. Mahoney, J. Verghese, Relationship of gait and cognition in the elderly, Curr. Transl. Geriatr. Exp. Gerontol. Rep. 2 (2013) 167-173.

[9] S. Lord, L. Rochester, V. Hetherington, L.M. Allcock, D. Burn, Executive dysfunction and attention contribute to gait interference in 'off'state Parkinson's Disease, Gait Posture 31 (2010) 169-174.

[10] C. Tard, K. Dujardin, J.-L. Bourriez, A. Destée, P. Derambure, L. Defebvre, et al., Attention modulates step initiation postural adjustments in Parkinson freezers, Parkinsonism Relat. Disord. 20 (2014) 284-289.

[11] C. Curtze, J.G. Nutt, P. Carlson-Kuhta, M. Mancini, F.B. Horak, Levodopa is a double-edged sword for balance and gait in people with Parkinson's disease, Mov. Disord. 30 (2015) 1361-1370. 
[13] R. Camicioli, B.S. Oken, G. Sexton, J.A. Kaye, J.G. Nutt, Verbal fluency task affects gait in Parkinson's disease with motor freezing, J. Geriatr. Psychiatry Neurol. 11 (1998) 181-185.

[14] J. Spildooren, S. Vercruysse, K. Desloovere, W. Vandenberghe, E. Kerckhofs, A. Nieuwboer, Freezing of gait in Parkinson's disease: the impact of dual-tasking and turning, Mov. Disord. 25 (2010) 2563-2570.

[15] D.S. Peterson, B.W. Fling, M. Mancini, R.G. Cohen, J.G. Nutt, F.B. Horak, Dual-task interference and brain structural connectivity in people with Parkinson's disease who freeze, J. Neurol. Neurosurg. Psychiatry (2014), http://dx.doi.org/10.1136/ jnnp-2014-308840.

[16] C. Schlenstedt, M. Muthuraman, K. Witt, B. Weisser, A. Fasano, G. Deuschl, Postural control and freezing of gait in Parkinson's disease, Parkinsonism Relat. Disord. 24 (2016) 107-112.

[17] S. Mellone, M. Mancini, L.A. King, F. B. Horak, L. Chiari, The quality of turning in Parkinson's disease: a compensatory strategy to prevent postural instability? J. Neuroeng. Rehabil. 13 (2016) 1.

[18] A. Nieuwboer, L. Rochester, T. Herman, W. Vandenberghe, G.E. Emil, T. Thomaes, et al., Reliability of the new freezing of gait questionnaire: agreement between patients with Parkinson's disease and their carers, Gait Posture 30 (2009) 459-463.

[19] C.G. Goetz, B.C. Tilley, S.R. Shaftman, G.T. Stebbins, S. Fahn, P. Martinez-Martin, et al., Movement disorder society-sponsored revision of the unified Parkinson's disease rating scale (MDS-UPDRS): scale presentation and clinimetric testing results, Mov. Disord. 23 (2008) 2129-2170.

[20] G.T. Stebbins, C.G. Goetz, D.J. Burn, J. Jankovic, T.K. Khoo, B.C. Tilley, How to identify tremor dominant and postural instability/gait difficulty groups with the movement disorder society unified Parkinson's disease rating scale: comparison with the unified Parkinson's disease rating scale, Mov. Disord. 28 (2013) 668-670.

[21] F. Franchignoni, F. Horak, M. Godi, A. Nardone, A. Giordano, Using psychometric techniques to improve the Balance Evaluation Systems Test: the mini-BESTest, J. Rehabil. Med. 42 (2010) 323-331.

[22] M. Mancini, A. Salarian, P. Carlson-Kuhta, C. Zampieri, L. King, L. Chiari, et al., ISway: a sensitive, valid and reliable measure of postural control, J. Neuroeng. Rehabil. 9 (2012) 1.

[23] A. Salarian, F.B. Horak, C. Zampieri, P. Carlson-Kuhta, J.G. Nutt, K. Aminian, iTUG a sensitive and reliable measure of mobility, IEEE Trans. Neural Syst. Rehabil. Eng. 18 (2010) 303-310.

[24] V.E. Kelly, C. Johnson, E.L. McGough, A. Shumway-Cook, F. Horak, K. Chung, et al., Association of cognitive domains with postural instability/gait disturbance in Parkinson's disease, Parkinsonism Relat. Disord. 21 (2015) 692-697.

[25] R. Roemmich, J. Elrod, Effects of cognitive task on gait initiation in Parkinson disease: evidence of motor prioritization? J. Rehabil. Res. Dev. 50 (2013) 699.

[26] A. Plate, K. Klein, O. Pelykh, A. Singh, K. Bötzel, Anticipatory postural adjustments are unaffected by age and are not absent in patients with the freezing of gait phenomenon, Exp. Brain Res. (2016) 1-10.

[27] J.V. Jacobs, J.G. Nutt, P. Carlson-Kuhta, M. Stephens, F.B. Horak, Knee trembling during freezing of gait represents multiple anticipatory postural adjustments, Exp. Neurol. 215 (2009) 334-341.

[28] B.W. Fling, R.G. Cohen, M. Mancini, J.G. Nutt, D.A. Fair, F.B. Horak, Asymmetric pedunculopontine network connectivity in parkinsonian patients with freezing of gait, Brain 136 (2013) 2405-2418.

[29] G. Vervoort, E. Heremans, A. Bengevoord, C. Strouwen, E. Nackaerts, W. Vandenberghe, et al., Dual-task related functional connectivity alterations in patients with Parkinson's disease and Freezing of Gait, Neuroscience (2016).

[30] B.R. Bloem, Y.A.M. Grimbergen, J.G. van Dijk, M. Munneke, The posture second strategy: a review of wrong priorities in Parkinson's disease, J. Neurol. Sci. 248 (2006) 196-204. 